Regards sur l'économie allemande

Bulletin économique du CIRAC

$68 \mid 2004$

Varia

\title{
L'Allemagne sur la voie de nouveaux équilibres
}

\section{René Lasserre}

\section{OpenEdition}

\section{Journals}

Édition électronique

URL : http://journals.openedition.org/rea/3614

DOI : 10.4000/rea.3614

ISBN : 978-2-8218-0832-4

ISSN : 1965-0787

Éditeur

CIRAC

Édition imprimée

Date de publication : 1 octobre 2004

Pagination : 1-2

ISSN : 1156-8992

Référence électronique

René Lasserre, "L'Allemagne sur la voie de nouveaux équilibres », Regards sur l'économie allemande [En ligne], 68 | octobre 2004, mis en ligne le 29 avril 2009, consulté le 22 septembre 2020. URL : http:// journals.openedition.org/rea/3614 ; DOI : https://doi.org/10.4000/rea.3614 


\title{
L'Allemagne sur la voie de nouveaux équilibres
}

\begin{abstract}
S'appuyant sur une industrie puissante et globalisée, l'économie allemande a su tirer parti de la reprise mondiale et a renoué durablement avec la croissance. Celle-ci demeure cependant contenue, moins en raison des incertitudes internationales, que sous l'effet d'un marché domestique anémique qui ne parvient décidément pas à rebondir. L'économie allemande reste tirée vers le bas par une demande intérieure ralentie et un marché de l'emploi déprimé. Le "modèle " semble enfermé dans une impasse systémique : l'activité exportatrice assure l'essentiel de la dynamique économique du pays, mais sous l'effet de coûts internes trop élevés, elle ne peut y parvenir qu'au prix d'un effort incessant de rationalisation de la production industrielle et de relocalisation des activités à l'échelle mondiale. L'un et l'autre sont préjudiciables à l'investissement et à l'emploi domestiques.
\end{abstract}

Le retour de la croissance ne permettra pas à lui seul de desserrer l'étau et de sortir de l'impasse. Face à une concurrence mondiale renforcée par l'émergence de nouveaux compétiteurs en Asie du Sud Est et en Europe centrale, l'industrie allemande ne peut tirer son épingle du jeu qu'en réduisant ses coûts salariaux et en retrouvant de nouvelles marges de flexibilité. C'est à cette contrainte que répondent le processus de réajustement négocié du temps de travail engagé durant l'été dans les grands groupes industriels allemands, ainsi que le programme de restructuration salariale du groupe Volkswagen dont nous rendons compte dans ce numéro. A travers ces réajustements, les partenaires sociaux semblent franchir un nouveau pas sur la voie de la dérégulation contractuelle et de la flexibilisation salariale.

Les pouvoirs publics ne sont pas en reste : ils poursuivent courageusement la mise en œuvre de l'Agenda 2010 et la réforme incontournable des régimes de protection sociale. Avec la mise en œuvre, au $1^{\text {er janvier }}$ prochain, du dernier volet de la refonte du système d'indemnisation du chômage (Hartz $I V)$, le gouvernement n'hésite pas à braver l'impopularité. L'étude détaillée des mesures montre qu'il s'agit de promouvoir un dispositif qui, loin d'être socialement inéquitable comme le prétendent ses détracteurs, devrait inciter plus fortement les chômeurs, dans un contexte de croissance retrouvée, au retour à l'emploi. L'enjeu n'est pas mince au regard de l'inefficacité et du coût exorbitant du traitement social du chômage qui à lui seul absorbe près du quart du budget social. Avec l'assurance dépendance, c'est un nouveau chantier qui s'ouvre pour la réforme de la protection sociale : mis en place depuis moins de dix ans, ce dernier étage de l'Etat-Providence se trouve confronté au redoutable défi du vieillissement démographique. Reposant initialement sur le principe de répartition, son système de financement est d'ores et déjà périmé et devra faire place à un système fondé sur l'épargne individuelle. 
A travers ces réformes, c'est une fois de plus le coût du travail qui est en jeu : plus encore que le niveau des rémunérations qui a évolué très modérément au cours des dix dernières années écoulées, ou que le temps de travail dont la régulation conventionnelle permet de grandes marges de flexibilité, ce sont les coût salariaux annexes liés à la protection sociale qui constituent le principal handicap à la compétitivité des entreprises. Là encore, à travers la refonte en cours des régimes sociaux, l'Allemagne s'engage dans une refonte du système de solidarité dont le financement ne devrait plus être, à terme, exclusivement fondé sur l'activité productive, mais sur l'épargne et la responsabilités individuelles.

L'étude régionale sur le Brandebourg que nous présentons dans ce numéro montre par ailleurs combien, quinze ans après la chute du Mur, la question du déséquilibre économique entre l'Est et l'Ouest reste douloureuse et à quel point la solidarité interrégionale, pourtant coûteuse, trouve ses limites. Mais là encore, une nouvelle approche se dessine : sous la contrainte budgétaire, la politique de péréquation financière cède le pas à la promotion ciblée de pôles de compétitivité bien identifiés et, à l'instar de ce qui se pratique dans les Länder de l'Ouest, à la mise en œuvre de partenariats multiformes en matière de développement scientifique et d'innovation.

Confrontée à la double épreuve de l'unification et d'une globalisation accélérée, l'Allemagne unifiée émerge progressivement d'un difficile processus d'adaptation. Elle reconstruit son système de régulation économique et sociale sur de nouveaux équilibres. 